\title{
NMDA receptors are important regulators of pancreatic cancer and are potential targets for treatment
}

\author{
William G North ${ }^{1,2}$ \\ Fuli Liu' \\ Liz Z Lin' \\ Ruiyang Tian ${ }^{2}$ \\ Bonnie Akerman' \\ 'Department of Molecular and \\ Systems Biology, Geisel School of \\ Medicine at Dartmouth College, \\ ${ }^{2}$ Woomera Therapeutics Inc, Lebanon, \\ $\mathrm{NH}$, USA
}

This article was published in the following Dove Press journal:

Clinical Pharmacology:Advances and Applications

17 July 2017

Number of times this article has been viewed

\begin{abstract}
Pancreatic cancer, particularly adenocarcinoma of the pancreas, is a common disease with a poor prognosis. In this study, the importance of N-methyl-D-aspartate (NMDA) receptors for the growth and survival of pancreatic cancer was investigated. Immunohistochemistry performed with antibodies against GluN1 and GluN2B revealed that all invasive adenocarcinoma and neuroendocrine pancreatic tumors likely express these two NMDA receptor proteins. These proteins were found to be membrane components of pancreatic cancer cell lines, and both channel-blocker antagonist and GluN2B antagonist significantly reduced cell viability in vitro. Both types of antagonists caused an internalization of the receptors. Dizocilpine maleate (MK-801) and ifenprodil hemitartrate both significantly inhibited the growth of pancreatic tumor xenografts in nu/nu mice. These findings predict that, as for other solid tumors investigated by us, pancreatic cancer could be successfully treated, alone or in combination, with NMDA receptor antagonists or other receptor-inhibiting blocking agents.
\end{abstract}

Keywords: pancreatic cancer, NMDA receptors, inhibitors, potential therapy

\section{Introduction}

Pancreatic cancer is the fourth leading cause of death from cancer throughout the world, and accounts for the loss of $\sim 40,000$ persons in the US each year. ${ }^{1-9}$ Although there have been several recent advances for treating this disease with surgery and adjuvant chemotherapy/radiation therapy, the estimated 5-year survival rate in the US is still only $7 \%$, with a $2 \%$ expected survival for those with distant disease. ${ }^{1}$ Therefore, a pressing need exists for new non-surgical methods of treatment that are effective in terms of providing long-term survival for patients, and for the development of non-invasive methods that can identify and monitor changes in tumor burden. The studies conducted and outlined in this communication indicate this need might be addressed through the use of agents that target the function of N-methyl-D-aspartate (NMDA) receptors as surface components. These receptors are ion-channels that are concentrated within the brain with limited peripheral expression and comprise protein heterotetromers. They are responsive to glycine (GluN1 component) and glutamate (GluN2 component). ${ }^{10,11} \mathrm{We}$ earlier reported NMDA receptors are commonly expressed by human neuroblastoma, breast cancer, small-cell lung cancer, and ovarian cancer, and blockade of these receptors inhibit tumor growth. ${ }^{12-15}$ A potential complication in the use of such NMDA receptor blockade could be expected from reports of autoimmune encephalitis that can occur in some cancer patients through the generation of antibodies to NMDA receptors. ${ }^{16-18}$ However, this malady seems to be principally due to a rare central inflammatory reac-
Correspondence: William G North Department of Molecular and Systems Biology, Geisel School of Medicine at Dartmouth College, I Medical Center Drive, Lebanon, NH 03756, USA

Tel +l 6036507736

$\mathrm{Fax}+\mathrm{I} 6036506130$

Email William.G.North@Dartmouth.Edu 
tion, and NMDA antagonists has been successfully introduced for therapy in the treatment of Alzheimer's disease and post traumatic stress disorder, without serious side effects. ${ }^{19-21}$ Additionally, During et $\mathrm{al}^{22}$ performed oral vaccination against GluN1 in mice and found there were no noticeable pathological effects induced through this treatment. To the contrary, the treated animals appeared to be afforded some protection to the central nervous system against chemical injury. Such findings, therefore, seem to address concerns for future pancreatic cancer treatments to involve NMDA receptor blockade.

\section{Materials and methods}

\section{Cultured cell lines}

The human pancreatic cell lines PanC-1, HPAC-1, and BXCPC-3 cells were all obtained from American Tissue Type Collection (Rockland, MD, USA). Cells were grown and maintained in DMEM medium or RPMI 1640 (Mediatech, Inc., Herndon, VA, USA) supplemented with 10\% fetal bovine serum (Sigma-Aldrich Co., St. Louis, MO, USA) at cell densities of $10^{5}$ to $5 \times 10^{5} / \mathrm{mL}$ in a humidified atmosphere of $5 \% \mathrm{CO}_{2}$ at $37^{\circ} \mathrm{C}$.

\section{Antibodies}

The antibodies used were developed in rabbits to recognize unique peptide regions within the extracellular N-terminal domains of human GluN1 and GluN2B proteins (-MSIYSDKSIH-; -(Y)KDAHEKDDF-). These antibodies are referred to as PANN1 and MANDA2B and have been described previously ${ }^{13-15}$. PANN1 does not cross-react with GluN2 proteins, and MANDA2B does not cross-react with other GluN2 protein sub-types, at the dilutions used. Commercially available GluN1 antiserum from Cell Signaling, and GluN2 antiserum purchased from Santa Cruz (NMDARe2; Santa Cruz Biochemicals, Santa Cruz, CA, USA) were also employed. The latter commercial antiserum recognizes all NMDAR2 subunits.

\section{Immunohistochemistry}

Expression of GluN1 and GluN2B was evaluated in formalinfixed human pancreatic cancer and normal tissues using PANN1 and MANDA2B IgG antibody preparations diluted to $1: 10,000$ in phospate buffered saline (PBS)/0.4M NaCl containing 1\% horse serum (PSHS), and a Biogenex Supersensitive link-label immunohistochemistry-detection kit (Fremont, CA, USA). Tissues were from a commercial array of 10 cases of adenocarcinoma with normal adjacent tissues (Tissue Array Network, PA242), while an additional 20 cases of adenocarcinoma, and 3 cases of insulinoma, were obtained from an archival library of patient tissues at Dartmouth-Hitchcock Memorial Center. Tissue sections $(4 \mu \mathrm{m})$ were heated to $80^{\circ} \mathrm{C}$ for 20 minutes in citrate to recover antigen and then blocked by incubating them with $10 \%$ horse serum. They were then incubated for 1 hour at ambient temperature with PANN1 or MANDA2B (see above) at 1:10,000 dilution, alone, or in the presence of an excess of peptide antigen $(\sim 20 \mu \mathrm{M})$ as a negative control. Tissues were washed $(\times 3)$ and incubated for 1 hour at ambient temperature with biotinylated horse anti-rabbit $\mathrm{IgG}$, washed $(\times 3)$, then incubated for 1 hour at ambient temperature with Streptavidin coupled to peroxidase. Tissues were again washed $(\times 3)$ and finally reacted with a diaminobenzidine/ peroxide mixture and contrasted with hematoxylin.

\section{Confocal microscopy and flow cytometry}

For confocal studies, coverslips were seeded with 10,000 PanC-1, HPAC-1, and BXCPC-3 cells and generally grown to $100 \%$ confluence. The cells were fixed with formalin (Thermo Fisher Scientific, Waltham, MA, USA), permeabilized with 0.5\% NP40 (Sigma Aldrich Co.), blocked with phosphate buffered gelatin and stained overnight Co., at $4^{\circ} \mathrm{C}$ with a 1:500 serum equivalent dilution of an IgG preparation of our rabbit PANN1 antibodies (anti-GluN1) or MANDA2B antibodies (anti-GluN2B). Studies were repeated three times for each cell line. Alternatively, cells were reacted for one hour with these antibodies, then washed $(\times 3)$, fixed and permeabilized. Following these steps, five washings with $1 \%$ bovine serum albumen in PBS were carried out and cells incubated with a 1:2000 $(1 \mu \mathrm{g} / \mathrm{mL})$ dilution of the Alexa Fluor 488 goat anti-rabbit secondary antibody (Molecular Probes) for 60 minutes at ambient temperature. After further washing, cells were post-fixed with $4 \%$ paraformaldehyde and mounted in Vectashield (Vector Laboratories, Burlinghame, CA, USA) on glass slides. The final products were visualized with an Olympus BX61WI fluorescent confocal microscope employing a Hamamatsu Orca-ER C4742-80 camera. For flow cytometry, studies were performed on PanC-1 cells fixed with 4\% paraformaldehyde, incubated at ambient temperature for 2 hours with primary antibody (1:500), then for 1 hour with fluorescein isothiocyanate-labelled goat anti-mouse antibody (Pierce, Thermo \#31543) with intermittent washings throughout. Fluorescence on cells was then evaluated using an 8-Color MACSQuant Flow Cytometer of Miltenji Biotec (Cambridge, UK).

\section{Western blot analysis}

Cell lysates, and extracts from mouse organs, were prepared by sonication using a RIPA buffer solution (1\% NP-40, 1\% 
sodium deoxycholate, $0.1 \% \mathrm{SDS}, 150 \mathrm{mM} \mathrm{NaCl}, 25 \mathrm{mM}$ Trizma HCl, PH 7.4) with protease inhibitor (Hoffman-La Roche Ltd., Basel, Switzerland), the extracts centrifuged at $12,000 \times g$ for $4 \mathrm{~min}$, and the supernatant retained. The protein content of these extracts was assessed by differential absorbance measurements at $215 \mathrm{~nm}$ and $225 \mathrm{~nm}$. Aliquots each of each cell lysate $(\sim 25 \mu \mathrm{g}$ protein), or tissue extract $(\sim 50 \mu \mathrm{g}$ protein), were reduced using $50 \mathrm{mM}$ dithiothreitol heated in a boiling water bath for $5 \mathrm{~min}$, and separated on $12 \%$ gels by SDS-PAGE using Tris/Glycine/SDS buffer (25 mM Trizma, $192 \mathrm{mM}$ glycine, $0.1 \% \mathrm{SDS}, \mathrm{pH} 8.3$ ) at a voltage of $50 \mathrm{~V}$ for $10 \mathrm{~min}$, then at $75 \mathrm{~V}$ for $\sim 2$ hours at ambient temperature or at $100 \mathrm{~V}$ for 1 hour at $4^{\circ} \mathrm{C}$. The proteins were transferred onto Immobilon-P polyvinylidene difluoride membrane (EMD Millipore, Billerica, MA, USA) in Tris/glycine/SDS buffer with $6 \%$ methanol, using the MiniProtean 3 system from BioRad Laboratories Inc. (Hercules, CA, USA). The membrane was incubated with Superblock PBS buffer (Thermo Fisher Scientific), followed by incubation with 1:300 dilutions of PANN1 or MANDR2B antibodies following their isolated using antigen-affinity chromatography. The commercial antisera described above were also employed to identify proteins. Western blots were visualized using horseradish peroxidaselabeled goat anti-rabbit antibody (7074, Cell Signaling Technology), SuperSignal WestDura Extended Duration Substrate (Thermo Fisher Scientific), and a FluoroChem 8900 imager. The blots were stripped and incubated with anti-GAPDH (Chemicon), or scanned with anti- $\beta$-actin (Sigma Aldrich Co.,), to ensure equal protein loading.

\section{Cell viability assay}

Cells cultures (PanC-1, HPAC-1, and BXCPC-3) were treated with $0.05 \%$ trypsin, washed in DMEM medium and plated onto 96 well plates at $10^{4}$ cells/well in medium for 24 hours as previously described. ${ }^{15}$ Incubation was then performed in DMEM containing 10\% FBS in the presence or absence of either the channel-blocker antagonist dizocilpine maleate (MK-801), anti-GluN2B (PanC-1 only), or the GluN2B antagonists ifenprodil hemitartrate and Ro-25-6981 maleate, at differing concentrations $(100-800 \mu \mathrm{M})$, and then MTT (Sigma Aldrich Co.,; $5 \mathrm{mg} / \mathrm{mL}$ diluted 10 -fold and incubated for 4 hours at $37^{\circ} \mathrm{C}$, then solubilized with SDS overnight following manufacturer's recommendations). Absorbance at $570 \mathrm{~nm}$ was recorded after 24 or 48 hours of incubation with antagonist using a Synergy HT Multi-Detection Microplate Reader. Cell viability was evaluated as percentage of vehicle control at the corresponding incubation time. In a similar manner, the effects on cell viability of affinity-chromatography purified PANN1 antibodies over 24 hours of incubation were examined. Amounts were based on dilutions from the original anti-serum but were evaluated as $<375$ fmole antibody at a dilution of $1: 10$

\section{Treatment of pancreatic tumor xenografts in mice}

Human subcutaneous tumor xenografts of pancreatic cancer cell line NCI PanC-1 were raised in nu/nu mice by injecting $1-2 \times 10^{7}$ cells into the right flank Tumors were allowed to grow for 4 weeks when they attained sizes $>300 \mathrm{~mm}^{3}$ and the influence on tumor growth of the channel-blocker receptor antagonist dizocilpine maleate (MK-801), and the GluN2B antagonist, ifenprodil, given intraperitoneally (i.p.), then examined. Tumor size was assessed by multiplying depth, width, and length, and these measurements were each made in triplicate for each tumor on a daily basis. The sizes obtained for each tumor during the study were expressed as a percentage of the size measured on day zero of treatments. Percentage tumor growth in a control group of animals receiving i.p. PBS vehicle $(n=8)$ was compared to percentage tumor growth in animals $(n=8)$ receiving Dizocilpine maleate $(0.3$ $\mathrm{mg} / \mathrm{kg}$ body weight) twice daily, or ifenprodil $(2.5 \mathrm{mg} / \mathrm{kg}$ body weight), once daily, over 10 days.

\section{Statistical evaluations}

Results were evaluated by analysis of variance (ANOVA) and the Student-Neuman-Kuels test. Longitudinal growth data was evaluated using repeated measures ANOVA. Significance was determined to be present for $p<0.05$.

\section{Assurance for human and animal studies}

Approval for the use of human tissues for these studies was provided by the Institutional Review Board of Dartmouth College under human subject assurance number 00003095, and with written informed consents signed by all patients. Animal studies were approved by the Institutional Animal Care and Use Committee (IACUC) of Dartmouth College, an Association for Assessment and Accreditation of Laboratory Animal Care (AAALAC) approved facility, under animal welfare assurance number A3259-01.

\section{Results \\ NMDA receptor expression in common to pancreatic cancer}

The Avidin-Biotin complex technique of immunohistochemistry revealed the presence of GluN1 and GluN2B in seemingly all neoplastic cells of all tumor tissue microdots and of all sections, including three defined by others as 
neuroendocrine tumors. Most cancer types were defined as adenocarcinoma of the pancreas. Staining was intense at $\times 3$ to $\times 4$ intensity and was completely blocked when antibodies were used in the presence of excess peptide antigen (Figure 1). Using the same conditions, no staining was found with normal human pancreas, ovary, kidney, breast, and lung tissues. No detectable GluN1 or GluN2B proteins were present in Western blot profiles of extracts from normal mouse pancreas, ovary, kidney, lung, liver, heart, intestine, and skeletal muscle, but both were clearly present in extracts from brain (data not shown).

\section{NMDA receptors are present on pancreatic cancer cell lines}

GluN1 and GluN2B were both clearly present on the surface of PanC-1, HPAC-1, and BXCPC-3 cells demonstrated by confocal microscopy and by Flow Cytometry (Figure 2A-D). When viable cells were reacted with antibodies at $37^{\circ} \mathrm{C}$, all fluorescent staining was found as concentrated pockets within the cell cytoplasmic interior showing that the antibody-receptor complexes became internalized. Western analysis performed on cell extracts also revealed the presence of both of GluN1 and GluN2B receptor proteins (data not shown).

\section{Blockade of NMDA receptors decreases cancer cell viability}

When pancreatic PanC-1, HPAC-1 and BXCPC-3 cancer cells were treated for 48 hours with increasing concentrations of the channel-blocker antagonist MK-801 (dizocilpine maleate) there were dramatic reductions in cell viability indexed by the MTT method with significant changes $(p<0.01)$ produced with doses of $200 \mu \mathrm{M}$ antagonist, and a reduction to less than $50 \%$ controls $\left(\mathrm{IC}_{50}\right)$ produced most generally by doses of
400-500 $\mu \mathrm{M}$ (Table 1). A preparation of our polyclonal antibodies against GluN2B as a protein A isolated IgG fraction, also demonstrated a capacity to almost completely impair the viability of PanC-1 pancreatic cancer cells, with a greater than $50 \%$ reduction being produced at a dilution of $1: 300$ related to the concentration of antibodies in the original antiserum. Similarly, as found for MK-801, the GluN2B specific antagonists ifenprodil hemitartrate and Ro-25-6981 maleate produced reduced viability of PanC- 1 cells by $\sim 90 \%$ with a dose range of $200-800 \mu \mathrm{M}$. Ifenpodil was found to be every bit as effective as the irreversible channel-blocking inhibitor MK801, producing $\mathrm{IC}_{50} \mathrm{~s}$ from $250-600 \mu \mathrm{M}$ ), and after 24 hours of incubation generating an average linear regression of $\mathrm{y}=-0.127+102.04$ with an $\mathrm{R}^{2}$ of 0.989 and an $\mathrm{IC}_{50}$ of 442 $\mu \mathrm{M}$ over four studies (Figure 3 ).

\section{Tumor xenograft growth is prevented and size reduced by NMDA receptor antagonists}

Both the channel-blocker antagonist dizocilpine maleate (MK-801) and the GluN2B antagonist ifenprodil prevented growth of tumor xenografts of PanC-1 cells in nu/nu mice. While MK-801 prevented tumor growth, ifenprodil not only did this but also additionally reduce tumor size by almost half, and this reduction in size persisted 4 days after treatment was discontinued. Results for ifenprodil treatment are depicted in Figure 4. No adverse physiological or behavioral effects by treatments with either drug were apparent, and body weight gains of treated mice paralleled those of untreated animals.

\section{Discussion}

The findings of the studies conducted here demonstrated that NMDA receptors, particularly of the GluN1 receptor

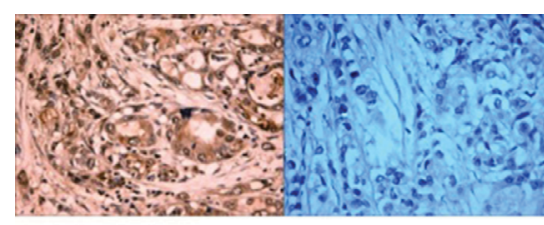

Patient 1

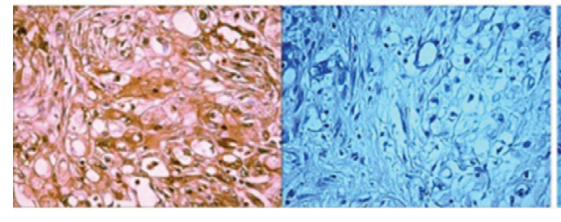

Patient 3

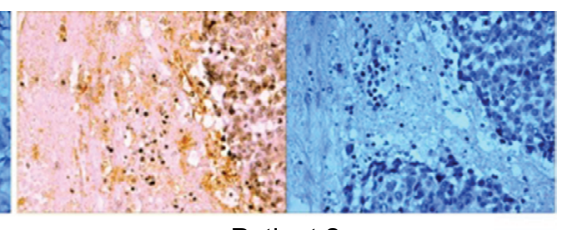

Patient 2

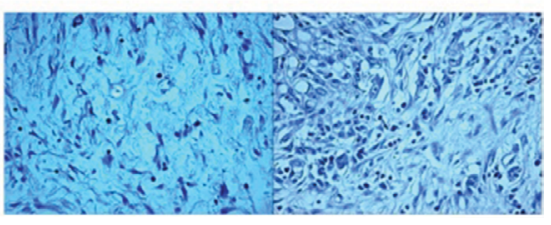

Normal tissue

Figure I Imunohistochemical staining of pancreatic cancers $(\times 20)$ from three patients with positive staining of tumors with GluN2B antibodies (left panels) and negative controls of GluN2B antibodies in the presence of excess peptide antigen (right panels).

Note: Two included normal pancreatic tissues, that give no staining with GluN2B antibodies (last two panels). 
A

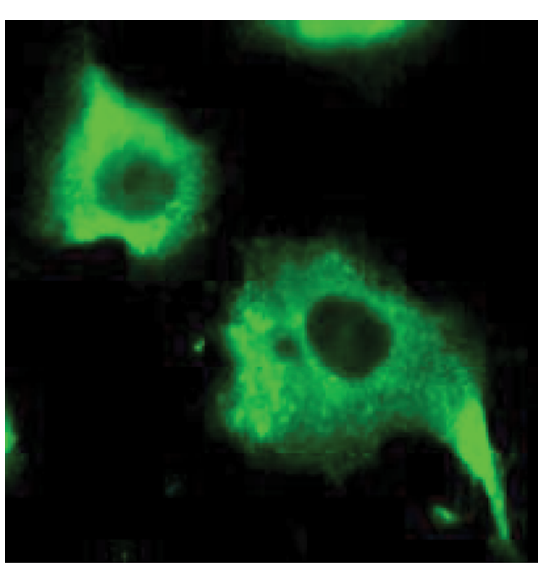

C

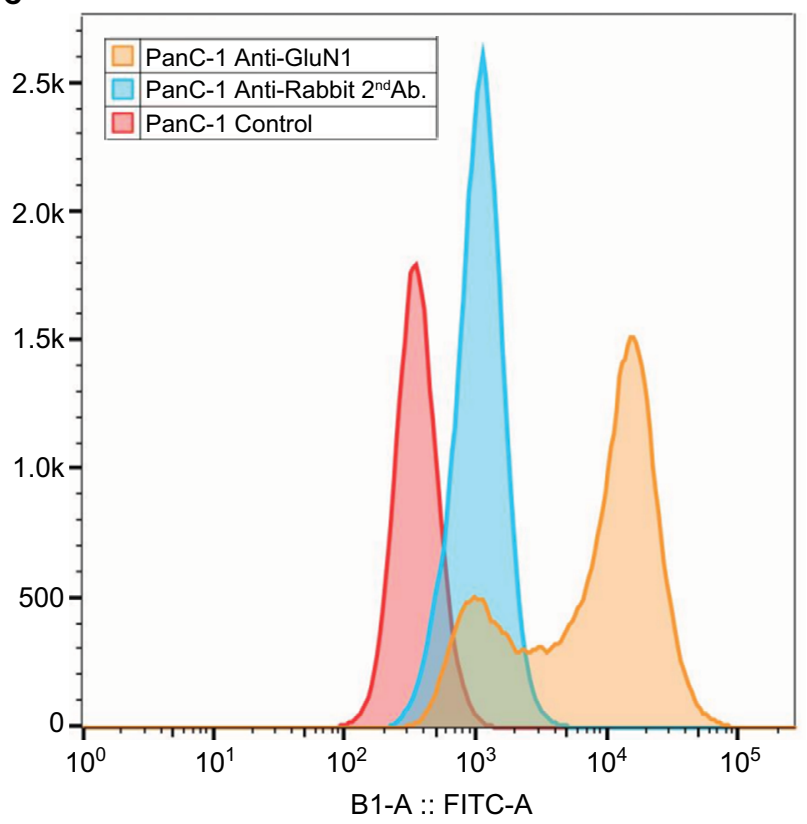

B

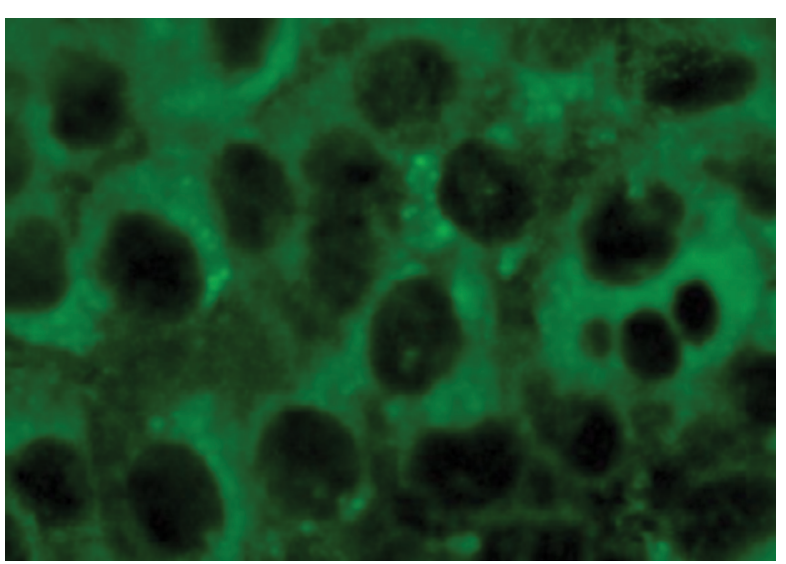

D

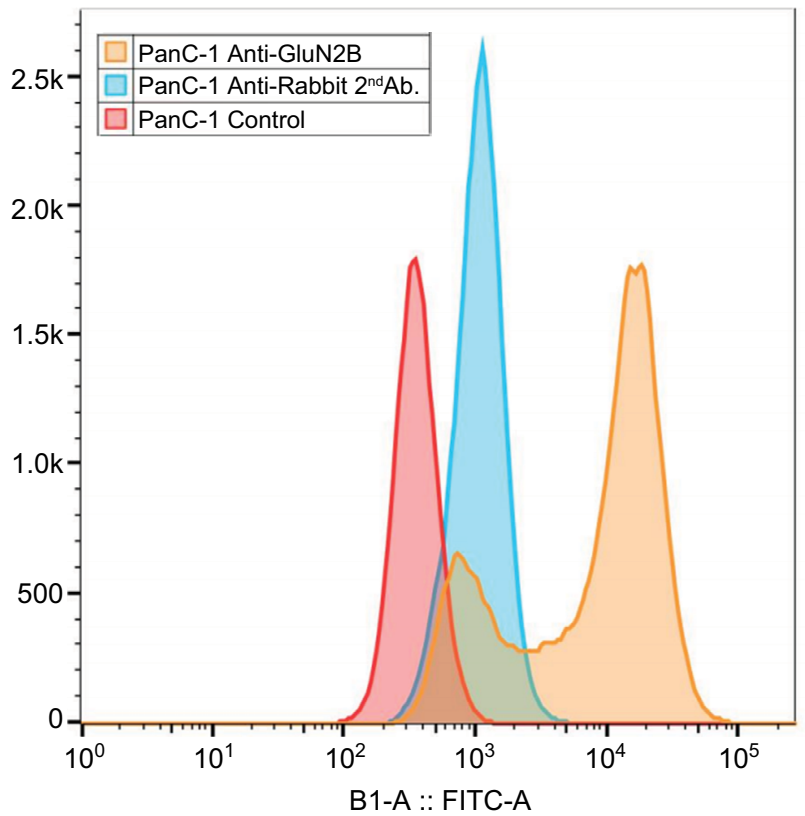

Figure 2 Demonstration of surface location of GluNI on pancreatic cancer cells.

Notes: Confocal images with PANNI antibodies on pancreatic cancer (A) PanC-I and (B) BXCPC-3 (magnification $\times 40$ ); Flow cytometry using second Ab fluorescence with (C) GluNI antibodies, and (D) GluN2B antibodies. Red and blue peaks are negative controls; indications are that $\sim 80 \%$ of cells have a positive reaction.

Abbreviation: FITC, fluorescein isothiocyanate.

Table I Dose (nearest $50 \mu \mathrm{M}$ ) of NMDA-antagonist (MK80I, ifenprodil, Ro25-698I) found to reduce pancreatic cell line (PanC-I, BXCPC3, HPAC) viability to $50 \%$ controls $\left(\mathrm{IC}_{50}\right)$ after 48 hours of incubation

\begin{tabular}{|c|c|c|c|}
\hline \multirow[t]{2}{*}{ Antagonist } & \multicolumn{3}{|c|}{$I C_{50}(\mu M)$} \\
\hline & PanC-I & $\mathrm{BXCPC3}$ & HPAC \\
\hline MK-80I, channel blocker & 600 & 400 & 600 \\
\hline Ifenprodil, GluN2B inhibitor & 400 & 250 & 500 \\
\hline Ro-25-698I, GluN2B inhibitor & 500 & 400 & 800 \\
\hline
\end{tabular}

Abbreviation: NMDA, N-methyl-D-aspartate.

protein sub-type coupled to the GluN2B receptor protein sub-type are present on most or all pancreatic cancers and are likely important factors for their growth and viability. Immunohistochemistry clearly showed this presence in tumor sections from patients and Western analysis showed them expressed in pancreatic cancer cell lines. Both confocal microscopy and flow cytometry confirm their location as components of plasma membranes of cells in long-term cultures. However, flow cytometry also indicates that up to $20 \%$ of cultured PanC- 1 cells may have low to undetectable levels of the NMDA proteins.

Our antibodies used in studies were generated to be specific for GluN1 or GluN2B but not distinguish between human and mouse forms, and clearly showed expression of both proteins in all three human cell lines examined. This is contrary to the finding reported by Malsy et $\mathrm{al}^{23}$ who failed to demonstrate the presence of GluN1 and GluN2B in PanC-1 cells, and report only the presence of GluN2A. We expect this failure to find GluN1 and GluN2B might reflect deficiencies of the commercial antibodies using the conditions employed 


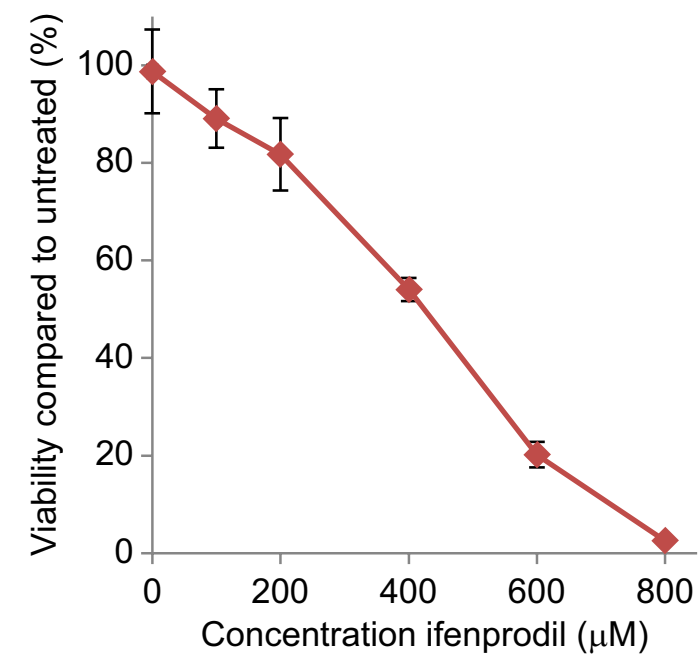

Figure 3 Influence of ifenprodil hemitartrate treatment for 24 hours on PanC-I pancreatic cancer cell viability $(n=8)$.

Notes: Values (SEM) are expressed as the percentage proliferation exhibited by cells in the absence of inhibitor.

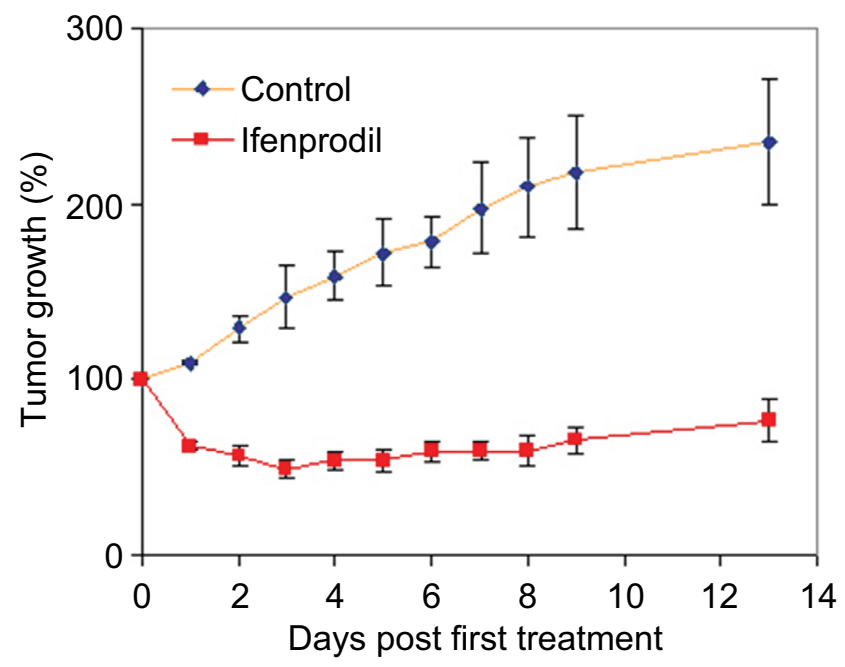

Figure 4 NMDAR receptor influence on the growth of human pancreatic tumor xenografts in nu/nu mice.

Notes: Administration of ifenprodil in daily dose of $2.5 \mathrm{mg} / \mathrm{kg}$ body weight for 10 days (days 0 through 9 ) significantly reduced size of PanC-I xenografts $(p<0.01, n=8)$ while having no apparent impact on animal health.

Abbreviation: NMDA, N-methyl-D-aspartate.

by them. That fully functional NMDA receptors are present on pancreatic cancer cells and tumors is evidenced by the finding that dizocilpine maleate (MK-801) inhibits vascular endothelial growth factor (VEGF) expression and growth cascade phosphorylation of PanC-1 cells in vitro and VEGF and growth of mouse pancreatic tumors (Panc02) in vivo. ${ }^{24,25}$ In contrast, while reported to be present and functional in some peripheral tissues, ${ }^{11}$ we were unable to demonstrate their presence in extracts of mouse tissues, except for brain, testes and uterus, by Western analysis. Thus, if present in these other tissues they would appear to be there in very low amounts or not involve GluN1 and GluN2B.
The viability of pancreatic cancer PanC-1, BXCPC3, and HPAC-1 cells was clearly reduced by the GluN1 antagonist and channel-blocker, dizocilpine maleate (MK-801), in a concentration dependent fashion, and by an antibody preparation of anti-GluN2B antibodies. BXCPC-3 and PanC- 1 cells were most affected with reductions to $\sim 10 \%$ of controls, while HPAC- 1 viability was only reduced to $\sim 40 \%$ of controls indicating lower dependence by this cell line. This difference suggests some variability could exist across tumors either regarding the importance of NMDA receptors to growth and survival, or the degrees of involvement of other GluN2 subtypes that were not researched for in this article. However, responses in many regards are very similar as shown by $\mathrm{IC}_{50}$ results of Table 1 . Very similar effects on these cells were produced by the specific GluN2B antagonist, ifenprodil, demonstrating that blockade of NMDA receptor activity through this receptor protein sub-type has the same influence as channel-blockers on pancreatic cancer cell viability and growth. As demonstrated by others, blockade of NMDA receptor activity in pancreatic cancer cells and tumors, and of other cancer types, not only impairs phosphorylated activation of proteins in growth cascades, but also inhibits VEGF generation and hence potential for metastasis. ${ }^{24-28}$

NMDA receptor blockade was found in our studies to have a profound effect on the growth of human pancreatic tumor xenografts derived from PanC-1 in nu/nu mice. The channel blocker dizocilpine maleate (MK-801) at a twice daily intraperitoneal dose of $0.3 \mathrm{mg} / \mathrm{kg}$ body weight completely inhibited the growth of these tumors that in vehicle controls grew to almost 3-times their original size. This finding for the action of MK-801 is similar to that recently reported by Chen et $\mathrm{al}^{24}$ for mouse PanC0 pancreatic tumors. Blockade through use of the GluN2B inhibitor, ifenprodil, was even more effective. As shown in Figure 4, a once daily intraperitoneal dose of $2.5 \mathrm{mg} / \mathrm{kg}$ body weight of this inhibitor produced a rapid shrinkage of tumors to $50 \%$ of their original size, and this size reduction was maintained after 4 additional days beyond treatment when final measurements were performed. The dosage of MK-801 employed here, while safe for mice and rats, is noted to produce both significant behavioral and locomotor effects, although it did not seem to significantly affect weight gain. However, the dosage of ifenprodil hemitartrate was well below doses known to have significant behavioral effects in rodents. ${ }^{29}$

The data from this and other studies allows us to conclude there is good reason for the potential use of NMDA receptor blockade, especially through the GluN2B sub-unit, for 
inclusion in the treatment of pancreatic cancer. To this end, infenprodil hemitartrate has long been approved for clinical use in France and Japan, while a similar compound, traxoprodil has been approved for clinical use in the US.

\section{Acknowledgments}

We are indebted to Nathan Sylvain, Chenoa Allen, AJ Vincelli, Aki Bowers, Hae-Lin Cho, and Cindy Sun for their technical support. This work was supported in part by the US Public Health Service grant R21 CA167329 to WGN.

\section{Author contributions}

WGN drafted the manuscript and was the chief architect of the research conducted. WGN, BA and FL were involved in performing confocal, cell-culture, RT-PCR, and binding studies. RT actively participated in performing and planning animal studies with WGN, and LZL, BA, and FL were jointly responsible for in vitro viability studies. All authors contributed toward drafting and revising the paper and agree to be accountable for all aspects of the work

\section{Disclosure}

The authors report no conflicts of interest in this work.

\section{References}

1. American Cancer Society. Cancer Facts \& Figures 2015. Available from: https://www.cancer.org/research/cancer-facts-statistics/all-cancer-factsfigures/cancer-facts-figures-2015.html.

2. Hariharan D, Saied A, Kocher HM. Analysis of mortality rates for pancreatic cancer across the world. HPB (Oxford). 2008;10(1):58-62.

3. Bakkevold KE, Arnesjø B, Kambestad B. Carcinoma of the pancreas and papilla of Vater presenting symptoms, signs, and diagnosis related to stage and tumour site. A prospective multicenter trial in 472 patients. Norwegian Pancreatic Cancer Trial. Scand J Gastroenterol. 1992;27(4):317-25.

4. Neoptolemos JP, Stocken DD, Friess H, et al. A randomized trial of chemoradiotherapy and chemotherapy after resection of pancreatic cancer. N Engl J Med. 2004;350(12):1200-1210.

5. Fesinmeyer MD, Austin MA, Li CI, De Roos AJ, Bowen DJ. Differences in survival by histologic type of pancreatic cancer. Cancer Epidemiol Biomarkers Prev. 2005;14(7):1766-1773.

6. Iacobuzio-Donahue CA, Maitra A, Shen-Ong GL, et al. Discovery of novel tumor markers of pancreatic cancer using global gene expression technology. Am J Pathol. 2002;160(4):1239-1249.

7. Demols A, Peeters M, Polus M, et al. Gemcitabine and oxaliplatin (GEMOX) in gemcitabine refractory advanced pancreatic adenocarcinoma: a phase II study. Br J Cancer 2006;94(4):481-485.

8. Eckel F, Schneider G, Schmid RM. Pancreatic cancer: a review of recent advances. Expert Opin Investig Drugs. 2006;15(11):1395-1410.

9. Mimeault M, Brand RE, Sasson AA, Batra SK. Recent advances on the molecular mechanisms involved in pancreatic cancer progression and therapies. Pancreas. 2005;31(4):306-316.
10. Carpenter D. NMDA receptors and the molecular mechanisms of excitotoxicity. In: Johnson P, Boldyrev AA, editors. Oxidative stress at the molecular, cellular, and organ levels. Trivandrum, India: Research Signpost. 2002:77-88.

11. Hinoi E, Takarada T, Ueshima T, Tsuchihashi Y, Yoneda Y. Glutamate signaling in peripheral tissues. Eur J Biochem. 2004;271(1):1-13.

12. North WG, Fay MJ, Du J, Cleary M, Gallagher JD, McCann FV. Presence of functional NMDA receptors in a human neuroblastoma cell line. Mol Chem Neuropathol. 1997;30(1-2):77-94.

13. North WG, Gao G, Memoli VA, Pang RH, Lynch L. Breast cancer expresses functional NMDA receptors. Breast Cancer Res Treat. 2010;122(2):307-314.

14. North WG, Gao G, Jensen A, Memoli VA, Du J. NMDA receptors are expressed by small-cell lung cancer and are potential targets for effective treatment. Clin Pharmacol. 2010;2:31-40.

15. North WG, Liu F, Tian R, Abbasi H, Akerman B. NMDA receptor are expressed in human ovarian cancer tissues and ovarian cancer cell lines. Clin Pharmacol. 2015;7:111-117.

16. Tüzün E, Zhou L, Baehring JM, Bannikh S, Resenfeld MR, Dalmau J. Evidence for antibody-mediated pathogenesis in anti-NMDAR encephalitis associated with ovarian teratoma. Acta Neuropathol. 2009;118(6): 737-743.

17. Dalmau J, Gleichman AJ, Hughes EG, et al. Anti-NMDA encephalitis:case series and analysis of the effects of antibodies. Lancet Neurol. 2008;7(12): 1091-1098.

18. Will A, Akalin M. Paraneoplastic limbic encephalitis with NMDA receptor (NR1) antibodies in breast cancer. Neurology. 2012;78(Meeting Abstracts 1):S08.007.

19. Sonkusare SK, Kaul CL, Ramarao P. Dementia of Alzheimer's disease and other neurodegenerative disorders-memantine, a new hope. Pharmacol Res. 2005;51(1):1-17.

20. Plosker GL, Lyseng-Williamson KA. Memantine: a pharmacoeconomic review of its use in moderate-to-severe Alzheimer's disease. Pharmacoecon. 2005;23(2):193-206.

21. Sasaki T, Hashimoto K, Okawada K, et al. Ifenprodil for the treatment of flashbacks in adolescent female posttraumatic stress disorder patients with a history of abuse. Psychother Psychosom. 2013;82(5):344-345.

22. During MJ, Symes CW, Lawlor PA, et al. An oral vaccine against NMDAR1 with efficacy in experimental stroke and epilepsy. Science. 2000;1453-1460.

23. Malsy M, Gebhardt K, Gruber M, Wiese K, GrafB, Bundscherer A. Effect of ketamine, s-ketamine, and MK-801 on proliferation, apoptosis, and necrosis in pancreatic cancer cells. BMC Anesthesiol. 2015;15:111-123.

24. Chen X, Wu Q, You L, Chen S, Zhu M, Miao C. Propofol attenuates pancreatic cancer malignant potential via inhibition of NMDA receptor. Eur J Pharmacol. 2016;795:150-159.

25. Tachibana N, Shirakawa T, Ishii K, et al. Expression of various glutamate receptors including N-methyl-D aspartate receptor (NMDAR) in ovarian teratoma removed from a young woman with anti-NMDAR encephalitis. Intern Med. 2010;49(19):2167-2173.

26. Stepulak A, Sifringer M, Rzeski W, et al. NMDA antagonist inhibits the extracellular signal-regulated kinase pathway and suppresses cancer growth. Proc Natl Acad Sci U S A. 2005;102(43):15605-15610.

27. Stepulak A, Luksch H, Gebhardt C, et al. Expression of glutamate receptor sub-units in human cancers. Histochem Cell Biol. 2009;132(4): $435-445$.

28. Stepulak A, Rola R, Polberg K, Ikonomidou C. Glutamate and its receptors in cancer. J Neural Transm (Vienna). 2014;121(8):933-944.

29. Morales M, Spear LP. The effects of an acute challenge with the NMDA receptor antagonists, MK-801, PEAQX, and infenprodil, on social inhibition in adolescent and adult male rats. Psychopharmacology (Berl). 2014;231(8):1797-1807. 
Clinical Pharmacology: Advances and Applications is an international, peer-reviewed, open access journal publishing original research, reports, reviews and commentaries on all areas of drug experience in humans. The manuscript management system is completely online and includes a very quick and fair peer-review system, which is all easy to use.

Submit your manuscript here: https://www.dovepress.com/clinical-pharmacology-advances-and-applications-journal
Visit http://www.dovepress.com/testimonials.php to read real quotes from published authors. 